\title{
TRAJETÓRIAS EDUCACIONAIS DE JOVENS RESIDENTES EM UM DISTRITO DA PERIFERIA DE SÃO PAULO*
}

\section{Mariana Bittar}

Centro de Estudos da Metrópole (CEM), São Paulo - SP, Brasil. E-mail: marianabittar@yahoo.com

DOI: http//dx.doi.org/10.17666/308947-61/2015

\section{Introdução}

Nas últimas décadas o tema da juventude ganhou espaço no meio acadêmico. Mais especificamente, as pesquisas sobre a relação dos jovens com a escola foram estimuladas pela persistência das desigualdades educacionais no Brasil. Se até os anos de 1980 o problema se concentrava na desigualdade de acesso, a partir daí a gradativa universalização do acesso foi acompanhada por fenômenos como a evasão e a repetência, a defasagem idade/série e a falta de domínio de aprendizagens fundamentais. ${ }^{1}$

* Este artigo apresenta os resultados da pesquisa realizada em minha tese de doutorado, Trajetórias educacionais dos jovens residentes num distrito com elevada vulnerabilidade juvenil, 2011.

Artigo recebido em 04/03/2013

Aprovado em 19/06/2015
Este artigo pretende contribuir para a pesquisa sobre as desigualdades educacionais dos jovens. Estamos interessados em investigar os mecanismos e as dinâmicas que podem afetar a sua trajetória escolar, provocando mudanças ou fortalecendo sua direção inicial. Para caracterizar o tipo de trajetória, observamos os seguintes elementos: distorção idade-série, reprovação, expulsão e evasão escolar. Exploramos de que forma os vínculos estabelecidos nas esferas de sociabilidade em que os jovens estão inseridos - a família, a escola, a vizinhança, o trabalho, os programas sociais, a igreja e o lazer - afetam suas trajetórias escolares. Além disso, investigamos em que medida eventos que ocorrem ao longo da vida do jovem podem afetar sua conduta, sua relação com os elos estabelecidos nos diferentes espaços de sociabilidade e, consequentemente, seus percursos educacionais.

$\mathrm{O}$ artigo está dividido em quatro seções além desta introdução. $\mathrm{Na}$ primeira, apresentamos os 
principais resultados das pesquisas sobre desigualdade educacional. Na segunda, detalhamos o objeto e o desenho da pesquisa. $\mathrm{Na}$ terceira, apresentamos as configurações encontradas em campo. Na quarta, sintetizamos as configurações, com ênfase nos efeitos das esferas de sociabilidade sobre as trajetórias escolares. A quinta é dedicada à conclusão.

\section{A pesquisa sobre desempenho educacional}

Encontramos dois grandes grupos de pesquisa sobre desempenho educacional - quantitativas e qualitativas. ${ }^{2}$ Características individuais e familiares aparecem na maioria das pesquisas quantitativas como importantes elementos explicativos das desigualdades educacionais. Os estudos apontam variáveis como renda domiciliar, escolaridade dos pais, raça, características do domicílio e mobilização dos pais com relação à escola ${ }^{3}$ (Barros et al., 2001; Menezes Filho e Ribeiro, 2009; Torres, Ferreira e Gomes, 2005).

Características da turma e da escola também ajudam a explicar o desempenho escolar dos alunos. A mistura social, as características do diretor, o percentual de professores concursados, a estabilidade do corpo docente e a infraestrutura escolar são algumas das variáveis explicativas identificadas nesses estudos (Menezes Filho e Ribeiro, 2009; César e Soares, 2001; Torres, Ferreira e Gomes, 2005).

As variáveis residenciais aparecem na pesquisa de Torres, Ferreira e Gomes (2005). O modelo indica que, embora variáveis individuais contribuam de forma significativa para a explicação do desempenho escolar, variáveis ecológicas, como o tipo de área de ponderação (periferia, de classe média ou de elite) e a proporção de migrantes recentes na área de residência, também são importantes para explicar a probabilidade de conclusão do ensino médio.

Os estudos quantitativos apresentam a vantagem de trabalharem com grandes escalas. No entanto, eles não conseguem captar os mecanismos e as dinâmicas que estão por trás das relações de causalidade identificadas. As pesquisas qualitativas buscam captar esses mecanismos.

Sá Earp (2006) e Mantovanini (2001) investigam em que medida a percepção do professor sobre o processo de aprendizado e sua atitude em sala de aula afetam o desempenho do aluno. As pesquisas apontam que a predição realizada pelo professor sobre o desempenho do aluno influencia não só a avaliação sobre ele, mas também, de forma paradoxal, o seu próprio desempenho. O fracasso escolar está fortemente relacionado com duas variáveis do processo pedagógico: o julgamento elaborado pelo professor sobre o rendimento escolar de seus alunos, em que se encontra implícita a decisão de quem vai ser aprovado e reprovado, e a avaliação da aprendizagem, utilizada pelo professor para justificar sua decisão anterior. Como veremos, esses são importantes elementos definidores das trajetórias escolares dos jovens aqui reunidos.

Silva (2006), por sua vez, destaca o progressivo distanciamento entre "os saberes pessoais dos jovens" e os "saberes propiciados pela instituição escolar". Para que os saberes escolares sejam alvo de um investimento do jovem, conclui a autora, é necessário que encontre relação entre estes e outros fora do âmbito escolar. Para tanto, é necessária a mobilização da equipe escolar.

A mobilização dos pais e o esforço individual aparecem como importantes elementos para a construção da trajetória escolar de sucesso em meios populares. O modo como pais e filhos se relacionam com as histórias escolares intergeracionais, os sentidos atribuídos a essas histórias e as disposiçôes a pensar, sentir e agir dos alunos em relação à escola são alguns dos mecanismos apontados pelos autores (Pereira, 2005; Lacerda, 2006).

A pesquisa realizada por Silva (2003) é a que mais se aproxima de nosso trabalho no sentido de como as diversas esferas de sociabilidade podem afetar a trajetória escolar dos jovens. Os instrumentos de pesquisa adotados são semelhantes - a análise dos relatos de vida e de questionários. $\mathrm{O}$ autor conclui que a permanência na escola decorre da dinâmica estabelecida entre as características singulares do sujeito e as redes sociais nas quais ele se insere. A conquista de uma posição privilegiada no campo escolar depende da compreensão, pelo aluno, das regras do jogo escolar. Outro elemento importante é a família - o juízo estabelecido pela família sobre a capacidade escolar dos filhos, o valor atribuído ao diploma escolar como instrumento de ascensão social e os investi- 
mentos realizados no campo escolar ajudam a explicar a permanência na escola. Por outro lado, assim como em nossa pesquisa, o autor encontrou importantes elos de apoio em outras esferas de sociabilidade. A identificação com indivíduos que circulam em espaços sociais, como a igreja e as entidades do bairro, exerce uma forte influência nas estratégias dos jovens.

No entanto, o foco de Silva são as trajetórias improváveis, ou seja, jovens residentes em uma favela do Rio de Janeiro que conseguiram vencer os obstáculos impostos e cursar o ensino superior. Em nosso trabalho, observamos a trajetória escolar como processo. Investigamos os mecanismos e as dinâmicas que podem afetá-las, provocando mudanças ou fortalecendo a sua direção inicial.

\section{As trajetórias escolares dos jovens}

A escola, nas últimas décadas, vem sofrendo um processo denominado por Dubet (1998) de "desinstitucionalização". A formação dos indivíduos que antes ocorria em esferas como a família, a escola e a igreja passa a depender cada vez mais das experiências individuais que dos moldes impostos por essas instituições. Os adolescentes trazem sua linguagem e cultura para dentro da escola, que perde o monopólio de "inculcar significações". O mundo da vida invade o espaço escolar, trazendo diversificação e fragmentação. Quatro experiências distintas emergem deste processo:

1. Alunos que "se socializam e se subjetivam na escola”. Seus interesses são convergentes com os estudos.

2. Alunos que vivem uma forte dissociação entre seus interesses e os estudos. Formam-se paralelamente à escola e se adaptam à vida escolar, sem que haja integração.

3. Alunos com dificuldade de construção de uma experiência escolar positiva e que sucumbem aos julgamentos escolares, que os classificam como "incapazes".

4. Alunos que reagem aos julgamentos escolares e querem escapar e salvar sua dignidade, voltando-se contra a escola.
Este estudo pretende investigar de que forma os elos estabelecidos nas diferentes esferas de sociabilidade em que os jovens estão inseridos afetam suas trajetórias escolares, provocando mudanças ou fortalecendo sua direção inicial. Observamos as seguintes esferas: a família, a escola, a vizinhança, o trabalho, os programas sociais, a igreja e o lazer. Além disso, analisamos em que medida eventos que ocorrem ao longo da vida do jovem - que denominamos "momentos de crise" - podem afetar a sua conduta, a relação com os elos estabelecidos nos espaços de sociabilidade e, consequentemente, as suas trajetórias escolares. Vale ressaltar, contudo, que não se pretende nesta pesquisa estabelecer tipologias passíveis de generalização, mas mostrar a pluralidade de situações encontradas em campo.

Entendemos como trajetórias escolares os percursos percorridos pelos indivíduos ao longo da sua vida escolar. Para caracterizar o tipo de trajetória, observamos os seguintes elementos: distorção idade-série, repetência, expulsão e evasão escolar. Inicialmente, pensamos nas trajetórias de forma dual. Por esta classificação, os jovens ficariam distribuídos em dois grupos antagônicos:

1. Alunos com trajetória escolar contínua (fluxo contínuo, sem reprovações, evasões ou elevada distorção idade-série);

2. Alunos com trajetória escolar descontínua (fluxo descontínuo e fragmentado, com reprovaçôes, evasões ou elevada distorção idade-série).

As situações encontradas em campo apontam, contudo, para algo mais complexo do que a dualidade. As trajetórias são dinâmicas, alteram-se em função da experiência concreta dos indivíduos e da forma como eles a vivenciam.

Nosso objeto de pesquisa se encontra na convergência entre os constrangimentos sociais e as percepções e condutas individuais. Buscamos explorar as diferenças entre as trajetórias escolares de jovens que pertencem a categorias sociais similares ou os processos que estruturam a realidade social e escolar desses jovens.

Sem reduzir a importância da sociedade na conformação das açôes e dos comportamentos, acreditamos que há um espaço de possibilidades 
dentro do qual o indivíduo opera. Os constrangimentos estruturais - ou seja, a situação socioeconômica e cultural da família, o local de moradia e a escola que frequenta - são elementos essenciais na definição das trajetórias escolares dos jovens. No entanto, a experiência concreta dos jovens nos diferentes espaços de sociabilidade em que transitam e, principalmente, a forma como a vivenciam e a interpretam guiarão suas escolhas e estratégias. Afinal, um indivíduo, evento ou ação só irá influenciar outro indivíduo se fizer sentido para ele (Elias, 2008; Dubet, 2005).

Os jovens são sujeitos ativos, fazem escolhas ao longo de sua trajetória de vida. Estabelecem laços de amizade e escolhem os espaços por onde transitam. Os elos constituídos nesses espaços afetam a forma como os eventos são vivenciados. Por outro lado, uma situação ou acontecimento particular pode ter impactos diferenciados sobre os indivíduos, dependendo da interpretação que eles dão ao fenômeno.

Adotamos técnicas de pesquisa etnográficas, visando um grupo específico de jovens - estudantes, evadidos ou que completaram o ensino médio ${ }^{4}$ em uma escola situada no distrito de Sapopemba. Este distrito apresentava, em 2009, a terceira maior concentração de jovens entre 15 e 19 anos e encontrava-se entre os distritos de São Paulo com maior índice de vulnerabilidade juvenil, de acordo com a Fundação Sistema Estadual de Análise de Dados (Seade).

A escola é uma das mais tradicionais do bairro. Os professores são majoritariamente moradores do bairro, da região ou dos municípios vizinhos, Santo André e São Bernardo. Ela é especializada no ensino médio, ${ }^{5}$ restando poucas matrículas no $2^{\circ}$ ciclo do ensino fundamental. ${ }^{6}$ O período matutino recebe apenas alunos do ensino médio; o vespertino concentra as turmas de II ciclo do ensino fundamental; o noturno atende alunos do ensino médio e da Educação de Jovens e Adultos. Assim como outras instituiçôes localizadas na periferia de São Paulo, a escola em questão tem enfrentado nos últimos anos uma elevada rotatividade de diretores e coordenadores, o que, segundo a equipe, tem resultado em descontinuidade do trabalho, desmotivação dos professores e funcionários e dificuldade de estabelecer regras estáveis de funcionamento da escola.

A maior parte dos jovens foi selecionada dentro da escola ou por indicação de entrevistados. Buscamos diversificar ao máximo o conjunto de entrevistados. Entrevistamos jovens matriculados nos períodos noturno e matutino; que tinham concluído o ensino médio naquela escola ou que tinham evadido. Procuramos indivíduos que apresentassem vínculos com as esferas de sociabilidade aqui investigadas, além de heterogeneidade em termos de cor, gênero e idade. Além disso, incluímos dois jovens que, como veremos na configuração 5, nunca frequentaram a escola objeto deste estudo e que, atualmente, não estudam. Incluímos esses casos em nossa amostra para entender os mecanismos que levam ao abandono escolar e explorar as dificuldades de reintegração na instituição.

A decisão por entrevistar alunos dos períodos noturno e matutino foi motivada pela observação inicial feita no espaço escolar e pelas entrevistas com a equipe gestora e com os docentes, que apontaram importantes diferenças quanto aos públicos desses turnos. Os jovens que frequentam o ensino médio diurno têm, em sua maioria, a vida escolar como principal atividade. Quando trabalham, as atividades ocorrem, geralmente, de forma esporádica e sem vínculo empregatício, o que pode levar a um comportamento mais agitado, aumentando os conflitos neste período. Já os alunos do noturno costumam apresentar vínculos mais estáveis de trabalho. O cansaço da jornada de trabalho faz com que esses jovens sejam mais calmos - ou "apáticos", como comentou a coordenadora do período.

Como a pesquisa tem um interesse especial na relação dos jovens com a política pública voltada para este público, visitamos duas importantes entidades sociais do bairro - o Centro de Defesa da Criança e do Adolescente (Cedeca) e o Cantinho da Esperança - e dois programas sociais - o Centro da Juventude e o Fábricas de Cultura. Selecionamos participantes desses programas que não frequentavam escola e que frequentavam a escola objeto deste estudo.

Realizamos entrevistas com dez alunos do período da manhã, seis do noturno e dois que migraram do ensino matutino para o noturno. Além disso, 
entrevistamos três ex-alunos - dois com ensino médio completo e um que havia evadido - e dois jovens que nunca frequentaram esta escola. Desse total, quinze eram meninos e oito meninas, 13 se autodeclararam brancos, quatro pardos e seis negros. $^{7}$

O trabalho de recuperação das histórias de vida e das esferas de sociabilidade não seguiu um padrão linear. Partimos das entrevistas com os jovens e, em um segundo momento, entrevistamos, sempre que possível, seus pais (aconteceu de o entrevistado não morar mais com eles ou simplesmente eles terem se recusado a responder a entrevista). Fizemos, então, uma nova rodada de entrevistas com as coordenadoras, procurando captar a visão da equipe escolar sobre os jovens. Por fim, quando identificamos uma situação de crise, tivemos um novo encontro para explorar a percepção do jovem sobre aquele momento, com ênfase nos efeitos da crise sobre suas trajetórias de vida e escolar.

Durante o período em que permanecemos em campo, adotamos ainda outros recursos, como a observação da rotina e da interação entre os diversos atores escolares, além da realização de uma série de conversas livres com eles e técnicos dos programas sociais. Esses foram importantes instrumentos para exploração dos mecanismos, das lógicas e dos processos que podem afetar a trajetória educacional dos jovens.

\section{Análise dos dados: as configuraçóes}

Os jovens apresentam diferenças quanto à idade, à cor, à renda familiar, às condições de moradia, ao tipo de família, à escolaridade e à situação dos pais ou responsáveis no mercado de trabalho. Esses fatores certamente influenciaram a sua trajetória escolar. No entanto, identificamos jovens com atributos e condições socioeconômicas similares, mas trajetórias escolares distintas. Nestes casos, as relações estabelecidas com os elos das esferas de sociabilidade e as formas como lidaram com as crises parecem explicar as diferenças encontradas.

Para explorar os efeitos que os elos estabelecidos nas diferentes esferas de sociabilidade exercem sobre a trajetória escolar dos jovens adotamos como referencial o conceito de configuração de Norbert Elias.
Segundo o autor, a sociedade é formada por grupos de indivíduos interdependentes, por configurações específicas que as pessoas formam umas com as outras:

[As] concepções tradicionais serão substituídas por uma visão mais realista das pessoas que, através das suas disposições e inclinações básicas são orientadas umas às outras das mais diversas maneiras. Estas pessoas constituem teias de interdependência ou configuraçôes de muitos tipos, tais como famílias, cidades, estratos sociais ou estados (Elias, 2008, p. 15).

Acreditamos também que o processo de socialização e de educação é afetado pelos laços estabelecidos em diferentes instâncias.

Em cada uma das narrativas observamos distintos arranjos entre as esferas de sociabilidade investigadas. ${ }^{8}$ Os jovens transitam por diferentes espaços, relacionam-se com vários indivíduos. Essas relações são dinâmicas, alteram-se ao longo do tempo, podendo afetar - positiva ou negativamente - sua trajetória escolar. Além disso, um importante elemento para a orientação ou reorientação dos percursos é a forma como eles vivenciam as situações de crise, os apoios recebidos e suas representações.

Em suma, as condutas dos jovens são influenciadas pelo contexto social em que vivem, mas também pela forma como interpretam e vivenciam as suas experiências. Devemos, assim, observar como esses dois eixos operam. Fizemos, portanto, um esforço para identificar configurações que exprimissem a variedade de situações encontradas em campo. Em cada configuração, uma ou mais esferas de sociabilidade se destacam na orientação ou reorientação das trajetórias escolares dos jovens ali incluídos. $\mathrm{O}$ fato de pertencerem à mesma configuração não significa, contudo, que as vivências e as representaçôes dos jovens sobre suas diversas esferas de sociabilidade sejam idênticas, mas que categorias comuns aparecem e dão pistas para a compreensão das trajetórias escolares.

Propomos seis configurações. Os jovens das três primeiras configurações apresentam trajetória escolar contínua, mudança no percurso escolar em sentido positivo ou projetos escolares e profissionais - importante estímulo para sua mobilização em relação à 
escola. Já os das três últimas apresentam trajetória escolar descontínua, mudança no percurso escolar em sentido negativo ou ausência de projetos escolares e profissionais. Apresentaremos, a seguir, de forma breve, cada uma das configuraçôes. Vale ressaltar, no entanto, que tais configuraçôes têm como objetivo destacar situaçôes encontradas em campo e não criar tipologias passíveis de generalização.

\section{Configuração 1: família como espaço privilegiado de definição da trajetória escolar}

Os seis jovens reunidos nesta configuração - três do sexo masculino e três do sexo feminino - confirmam o senso comum e parte da literatura que destaca a família como principal responsável pelo sucesso escolar. Essas famílias apresentam capital cultural elevado e condições de "transmissão" desse capital. A disponibilidade de tempo dos familiares, a valorização da escola e o interesse pelos conhecimentos ali adquiridos, o acompanhamento das atividades dos filhos e o fato de terem vivenciado a experiência escolar de forma positiva são alguns dos elementos associados na literatura ao sucesso escolar (Lahire, 2008; Charlot, 1996).

A família é o principal espaço de elaboração dos projetos escolares e profissionais desses jovens. A trajetória escolar positiva ou a mudança de percurso em sentido positivo está intimamente associada ao apoio recebido dos laços familiares. Seus pais e responsáveis não apenas valorizam a escolaridade como se mobilizam em relação à escola.

Essas famílias apresentam características peculiares - suas condições socioeconômicas e culturais são superiores às da média dos entrevistados: renda relativamente alta e boas condições de moradia. As mães ou responsáveis possuem ensino médio completo e disponibilidade de tempo para acompanhar as atividades das crianças. Os vínculos funcionam como fonte de apoio e, em certa medida, como ponte, ao estimular sua qualificação. ${ }^{?}$

A igreja, por sua vez, é utilizada como meio de disciplinar os jovens e evitar o seu envolvimento com o tráfico e outras atividades ilícitas - a grande preocupação da maioria das famílias residentes nesta área. Este grupo de entrevistados frequenta de forma assídua as instituiçōes religiosas do bairro e aponta importantes laços de amizade e de aconselhamento estabelecidos nesse espaço. A religião cumpre o papel sugerido por Setton, ou seja, de forma complementar à família e à escola, funciona como um espaço produtor "de valores morais e identitários [...], um sistema de disposiçôes orientador de condutas" (Setton, 2008, pp. 15-16).

De um modo geral, eles possuem uma boa relação com a equipe escolar. Apontam importantes laços neste espaço - professores, coordenadores e alunos aparecem em suas falas. Para o corpo docente, o sucesso escolar está intimamente associado à estrutura familiar - famílias "estruturadas" geram alunos que não dão trabalho e que, por esse motivo, possuem bom desempenho escolar. Estes jovens confirmam a "predição inicial" dos docentes. Eles ocupam o centro da sala de aula. São para esses alunos que eles destinam seu esforço. O resultado é o sucesso escolar.

\section{Configuração 2: Escola como espaço primordial de definição da trajetória escolar}

De modo distinto da primeira configuração, os três jovens aqui reunidos - dois do sexo masculino e um do sexo feminino - parecem negar o "senso comum" de que uma família desestruturada ou a falta de apoio dos pais leva necessariamente a uma trajetória escolar descontínua. Apesar das condições familiares adversas, eles apresentam trajetórias escolares contínuas e, talvez o mais importante, ambiciosos projetos para o futuro.

A família não é considerada esfera relevante para a construção desses projetos. Ao contrário, muitas vezes, o que notamos é a situação inversa os elos familiares atuam de forma negativa -, como obstáculo ao seu desenvolvimento. $\mathrm{O}$ progresso educacional desses jovens parece estar mais associado à sua capacidade de estabelecer limites em seus laços familiares do que ao apoio que recebem deles.

Filhos de imigrantes, eles pertencem a famílias com condiçôes socioeconômicas e culturais limitadas. Suas mães possuem baixa escolaridade. Não contam com o apoio dos pais e sua trajetória familiar é marcada por crises. No entanto, os elos estabelecidos em outras esferas de sociabilidade compensam os efeitos negativos da família. A esfera 
primordial para a definição das trajetórias educacionais desses jovens é a escolar. Os principais projetos e decisóes sobre a escola são elaborados com o apoio de laços estabelecidos nesse espaço.

Diversos autores destacam a importância das relações estabelecidas entre a equipe escolar e os alunos na definição do desempenho. Assim como as relações familiares, as experiências e as relações estabelecidas no espaço escolar são elementos decisivos na construção do papel de aluno (Torres et al., 2005; Dayrell, 1996; Mantovanini, 2001; Sá Earp, 2006).

Esses três jovens, assim como os da primeira configuração, são exemplos de alunos que confirmam a "predição inicial" dos docentes - considerados bons alunos, desenvolvem uma relação positiva com professores e coordenadores e conseguem atingir o êxito. Embora apontem problemas na escola como o desinteresse de certos professores e a ausência de regras claras e estáveis -, eles parecem não afetar sua experiência positiva.

Outras esferas também aparecem nos relatos. Os elos estabelecidos na igreja funcionam como importantes fontes de apoio para um dos jovens. Eles impedem que a crise familiar afete sua trajetória educacional. De forma similar, os vínculos criados na vizinhança e a participação em programas sociais são identificados pelos outros dois entrevistados como importantes fontes de apoio para a superação das crises familiares e a formulação de projetos escolares e profissionais.

\section{Configuração 3: Trabalho como espaço primordial de definição da trajetória escolar}

Os dois jovens (ambos do sexo masculino) aqui reunidos apresentam uma inversão da expectativa vigente dos ciclos de vida, ou seja, de que os indivíduos se movem do ambiente familiar para o escolar e deste para o profissional. A antecipada inserção no mercado formal de trabalho afeta as decisóes escolares desses jovens (Guimarães, 2005). Suas trajetórias educacionais mais recentes e seus projetos escolares e profissionais são afetados pela experiência e pelos vínculos estabelecidos no trabalho. Embora cansados, sentem-se motivados a dar continuidade aos estudos para progredir na carreira profissional.
Eles não apresentam grande diferença de idade com relação aos outros entrevistados. Filhos de imigrantes, eles possuem renda familiar e condições de moradia similares a dos jovens da primeira configuração.

A esfera familiar apresenta impacto negativo na trajetória educacional de um dos jovens. Ele relata uma história familiar marcada por mudanças de cidade, separaçôes, reencontros e a morte do pai. Esses eventos impactaram seu percurso escolar, marcado por mudanças frequentes de escola, reprovaçóes e evasão.Embora possua uma estrutura familiar mais estável - seus pais são casados, trabalham e são os principais provedores da casa -, o outro jovem entrevistado não identifica importantes elos neste espaço.

Os dois rapazes não apresentam trajetórias educacionais similares. Como mencionamos, uma delas é marcada por repetência, abandono e mudança de escola. No entanto, o emprego atual aponta para a possibilidade de uma inflexão em sua trajetória. O novo chefe colocou como condição de permanência no emprego, a conclusão do ensino médio. Já o segundo entrevistado, embora não apresente trajetória educacional descontínua, não identifica importantes elos na escola e fala dessa experiência sem entusiasmo. Uma nova possibilidade de trabalho, contudo, funciona como estímulo para a conclusão do ensino médio. Os projetos de futuro dos jovens desta configuração também são elaborados a partir da sua inserção no mercado de trabalho. A experiência profissional e os elos estabelecidos nessa esfera parecem reforçar a importância da conclusão do ensino médio e da inserção em outros níveis de ensino para o progresso profissional.

\section{Configuração 4: Obrigaçôes com a família e ausência de espaços alternativos de construção de projetos escolares}

Assim como na terceira configuração, as quatro jovens - todas do sexo feminino - aqui reunidas sofrem uma antecipação da expectativa vigente dos ciclos de vida. No entanto, para este grupo, o ingresso precoce na vida adulta parece limitar suas possibilidades futuras. Obrigações com a família casamento, nascimento de um filho e cuidado com os pais e irmãos - atuam como obstáculos ao seu desenvolvimento escolar e profissional. 
Filhas de imigrantes, elas pertencem a famílias com condições socioeconômicas e culturais limitadas. As condições de moradia são precárias e suas mães têm baixa escolaridade. Elas não contam com o apoio dos pais; ao contrário, os elos familiares parecem atuar como obstáculos ao seu desenvolvimento escolar. Por outro lado, de forma distinta dos jovens da segunda configuração, elas não encontram elos de apoio em outros espaços para a superação dos limites impostos pela família. Como resultado, notamos uma indiferença em relação aos assuntos escolares. Diferentemente dos alunos "considerados problema", elas passam despercebidas por professores e coordenadores, mas vão compor com aqueles a "periferia" da sala de aula. Trabalhos sobre desempenho escolar apontam que o local ocupado em sala de aula pode ser um importante determinante da trajetória escolar (Sá Earp, 2006; Mantovanini, 2001).

As jovens reunidas nesta configuração apresentam trajetórias escolares descontínuas ou tendência à inflexão negativa na trajetória. Nenhuma delas menciona projetos para o futuro. Além disso, todas possuem uma imagem negativa da escola, embora não tenham abandonado a instituição. $\mathrm{O}$ sentimento de incapacidade (decorrente da dificuldade de aprendizagem) e de desinteresse por parte do corpo docente provoca nos casos aqui analisados a desmobilização em relação à escola ou o retraimento. Como apontado por Dubet (2003), o fato de não obterem sucesso (apesar de seus esforços) faz com que elas decidam não participar mais do jogo, preservando, de certa forma, sua autoestima.

Duas jovens participam de programas sociais, sendo que uma delas relata o estabelecimento neste espaço de importantes elos sociais. Eles parecem funcionar como meio de superação dos limites impostos pela família. Estes laços ajudam-na a superar a timidez, ampliando sua rede de amizades, alterando seu comportamento em sala de aula e em outros espaços. O fortalecimento da sua autoestima altera sua postura com relação à escola. No entanto, o programa em questão é de curta duração (um ano e meio) e os participantes não são encaminhados para outros espaços de sociabilidade. Esse período de tempo pode ser insuficiente para a superação das dificuldades enfrentadas.
Configuraçāo 5: Relaçāo tensa com a escola e ausência de espaços alternativos de construção de projetos escolares

Os quatro jovens aqui reunidos - todos do sexo masculino - são os que apresentam conflitos mais frequentes com a equipe escolar. A relação tensa com a escola e a ausência de elos em outros espaços para a construção de projetos escolares provocam profundas descontinuidades em suas trajetórias - reprovações, evasões, mudanças de escolas e abandono.

Nesta configuração, incluímos dois jovens que participam do programa Centro da Juventude, ainda que não frequentem a escola. $\mathrm{O}$ objetivo é explorar a questão do abandono escolar e as dificuldades relatadas pela equipe dos programas sociais de estabelecer um elo de comunicação com a escola.

Como destaca Dubet (2003), a responsabilização dos alunos por mau desempenho provoca neles um sentimento de nulidade ou incapacidade. Observamos entre esses entrevistados dois movimentos apontados pelo autor como respostas a este processo: retraimento, como no caso das jovens da quarta configuração, e conflito, manifesto pela violência, desordem, agressão física e verbal aos professores.

Eles apresentam enormes dificuldades de adaptação às regras e normas escolares. Não veem relação entre a sua experiência de vida e os saberes propiciados em sala de aula. A promessa de um futuro melhor - obtenção de um certificado que garanta sua inserção no mercado de trabalho - é contrastada com a ausência de sentido nas atividades escolares cotidianas.

Como destaca Charlot (1996), o sentido que o aluno atribui à escola e sua consequente mobilização são elementos essenciais na determinação de seus percursos. O progressivo desinteresse desses jovens por assuntos escolares faz com que a instituição passe a ser vista não mais como um espaço de "apropriação de saberes", mas, apenas de sociabilidade.

Por outro lado, considerados alunos "fadados ao fracasso" e "instauradores da desordem", sua relação com a equipe escolar é marcada por conflitos. Ocupam a "periferia" da sala de aula. O comportamento e o desempenho desses jovens são associados a fatores externos à escola, como falta de apoio dos 
pais, desestrutura familiar e relaçōes precárias de trabalho. Sem saber como lidar com esses casos, a equipe gestora busca meios de transferir o problema para outras instituiçôes. A punição - reprovação, transferência de escola, expulsão - é entendida como único instrumento para garantir a disciplina.

A reação dos jovens parece ser o aumento da "zoeira" e da violência - brigas, depredação do espaço e do material escolar, uso de bebidas alcoólicas e drogas. Os alunos reprovados compóem as "piores" turmas da escola ${ }^{10}$ o que acaba por reforçar a indisciplina. Nos casos extremos, o resultado final, como veremos, é o abandono definitivo da escola. Os breves períodos de harmonia estão associados à atenção e ao estímulo por parte de determinado professor ou acolhimento de determinada turma.

Os entrevistados deste grupo pertencem a famílias com limitadas condiçôes socioeconômicas e culturais. Suas mães possuem baixa escolaridade e, quando trabalham, desempenham atividades marcadas pela precariedade. Suas relações familiares são marcadas por crises, separaçôes e mudanças. Tais vínculos afetam de forma negativa sua trajetória escolar.

A dificuldade de inserção no mercado formal de trabalho obriga esses jovens a exercerem atividades marcadas por intensa exploração, instabilidade e baixa remuneração. Isso resulta em faltas constantes, dificuldade de concentração e cansaço, prejudicando o rendimento escolar. Por outro lado, ao contrário dos jovens da terceira configuração, não encontram na esfera do trabalho importantes laços de apoio. Os únicos elos empenhados em reverter o processo de exclusão escolar são os estabelecidos nos programas sociais. Todos os jovens aqui reunidos frequentam esses espaços. E alguns apontam-nos como importantes fontes de apoio. ${ }^{11}$ Os agentes desses programas impedem a sua ruptura definitiva com a escola - exigindo a sua matrícula e permanência na instituição.

No entanto, a curta duração dos programas e a dificuldade de estabelecer diálogo com a equipe escolar podem impedir uma ação mais efetiva dos elos dessa esfera de sociabilidade sobre a trajetória desses jovens. Há uma grande disputa no bairro entre as duas instituiçōes. As organizações sociais reivindicam a inclusão dos jovens por elas aten- didos nas escolas da região, garantia prevista pelo Estatuto da Criança e do Adolescente. Sem saber como lidar com esses casos, a equipe escolar, por sua vez, busca meios de afastá-los. Como vimos, eles são vistos como alunos "fadados ao fracasso" e causadores de problemas.

Já para os dois jovens que abandonaram a escola, os elos estabelecidos nos programas sociais não são suficientes para garantir o seu reingresso na escola. Os técnicos relatam grande dificuldade em lidar com eles, que parecem reproduzir neste espaço o comportamento escolar. Há uma tentativa de autoafirmação através da "zoeira".

\section{Configuração 6: "mundo do crime" como espaço de ruptura da trajetória escolar}

Decidimos reunir três jovens - todos do sexo masculino - em uma mesma configuração porque duas características se destacam em suas trajetórias de vida: o vínculo com "o mundo do crime" 12 e a consequente ruptura com os elos construídos na esfera escolar. O desinteresse pelos assuntos escolares, a dificuldade de inserção no mercado de trabalho e a facilidade de acesso ao "mundo do crime" levam ao envolvimento desses jovens em tais atividades. A participação de diversos colegas em atividades criminais parece funcionar como um estímulo ao seu envolvimento. ${ }^{13}$

A justificativa adotada pelos jovens para o ingresso no crime é muito próxima à apontada por Bourdieu (1983) para a inserção no mercado de trabalho: a possibilidade de aquisição imediata de bens de consumo que lhes confiram status em seu grupo. ${ }^{14}$

A escola, por sua vez, funciona como um canal de inserção no mundo do crime. Isso ocorre por dois mecanismos. Primeiro porque ali se podem estabelecer vínculos com jovens envolvidos com atividades criminais; segundo porque ao excluir o aluno, ela fortalece seu laço com o "mundo do crime". A mera suspeita por parte da equipe escolar de envolvimento desses jovens em atividades criminais é suficiente para que eles sejam tratados como criminosos, passando a ocupar a periferia do espaço escolar. Os jovens reclamam da indiferença e do preconceito com que são tratados. Professores e coordenadores afirmam que esses alunos não de- 
veriam estar na escola - são considerados "má influência” para os outros alunos. Como resultado, eles decidem "abandonar o jogo". O mundo do crime ocupa o espaço deixado pela escola. Ao possibilitar a ampliação do status individual no grupo eles passam a ser respeitados pela comunidade, compram bens de consumo, as meninas passam a notá-los. Em suma, eles se encontram presos a um circulo vicioso: ao mesmo tempo que o ingresso no crime afeta sua trajetória escolar, a relação com a escola parece fortalecer os elos com esse mundo.

Os três jovens apresentam descontinuidades na trajetória escolar e ausência de projetos para o futuro. No entanto, o ingresso no mundo do crime não provoca a ruptura definitiva com a escola. Os elos familiares desempenham um importante papel nesse processo. Eles pertencem a famílias com limitadas condições socioeconômicas e culturais. As condições de moradia são regulares, mas a renda familiar é baixa. No entanto, as mães, embora possuam baixa escolaridade, enxergam a formação educacional como um importante instrumento de acesso ao mercado formal de trabalho e rompimento com o mundo do crime. Por este motivo, envolvem-se diretamente nos assuntos escolares.

Dois deles vivenciam situações de crise. No primeiro caso, como o jovem já havia evadido a escola, não é possível identificar relação entre a crise familiar e a experiência escolar. No segundo, a forma como as crises são vivenciadas e a ausência de apoio para superá-las afetam sua trajetória escolar. O assassinato do irmão e o estigma decorrente sofrido por ele e sua família deterioraram sua relação com a equipe escolar. Por outro lado, o período em que ficou internado na Fundação Casa ${ }^{15}$ e o preconceito com que é recebido na escola após a saída da instituição o afastou ainda mais da escola.

\section{Sintetizando as configuraçóes}

No Quadro 1, procuramos sintetizar alguns dos mecanismos encontrados em campo. Em cada linha do quadro - correspondente a uma configuração -, apresentamos o efeito dos laços estabelecidos nas esferas de sociabilidade - listadas nas colunas - sobre a trajetória escolar dos jovens ali reunidos. Destacamos em negrito as esferas que apareceram nos relatos dos jovens como determinantes de sua trajetória escolar ou das inflexões encontradas.

Os jovens das três primeiras configurações apresentam trajetória escolar contínua, mudança no percurso escolar em sentido positivo ou ambiciosos projetos para o futuro - estímulo fundamental para sua mobilização em relação à escola. $\mathrm{Na}$ configuração 1 , a esfera que se destaca na definição das trajetórias escolares é a familiar. Os principais projetos escolares e profissionais são elaborados com o apoio de laços familiares. Os elos estabelecidos na esfera religiosa, por sua vez, reforçam o papel da família ao disciplinar os jovens.

$\mathrm{Na}$ configuração 2, os elos estabelecidos em diferentes espaços de sociabilidade compensam os efeitos negativos da esfera familiar. As relaçōes familiares atuam como obstáculos ao desenvolvimento escolar dos jovens. No entanto, os entrevistados identificam na escola importantes fontes de apoio para superação das crises familiares e definição dos seus projetos escolares e profissionais. Além disso, vínculos estabelecidos em outras esferas - na igreja, na vizinhança e nos programas sociais - parecem reforçar o efeito da escola.

Os jovens dessas duas configurações parecem não ser afetados pelo processo de "desinstitucionalização" escolar descrito por Dubet (1998). A família, a escola e a igreja permanecem como espaços produtores de valores morais e identitários. Estas são as principais esferas de socialização desses jovens. Sua formação está associada aos moldes impostos por tais instituiçôes. Há uma convergência entre os seus interesses e os da escola.

$\mathrm{Na}$ configuração 3, a única esfera relevante para a definição das trajetórias escolares recentes dos jovens é o trabalho - os elos estabelecidos neste espaço reforçam a importância da conclusão do ensino médio e da continuidade dos estudos para o progresso profissional. A experiência escolar desses alunos aponta para o referido processo de "desinstitucionalização escolar". Frequentam a escola para obter o certificado de conclusão e, dessa forma, realizar seus projetos profissionais. Procuram se adaptar à vida escolar, mas não se sentem integrados nesse espaço. 


\section{Quadro 1 \\ Efeito das Esferas de Sociabilidade sobre as Trajetórias Escolares dos Jovens de Acordo com a Configuração}

\begin{tabular}{|c|c|c|c|c|c|c|}
\hline \multirow[b]{2}{*}{ Configuraçóes } & \multicolumn{6}{|c|}{ Esferas de Sociabilidade } \\
\hline & Família & Escola & Trabalho & Religiáo & $\begin{array}{l}\text { Programa } \\
\text { Social }\end{array}$ & $\begin{array}{l}\text { Vizinhança } \\
\text { Lazer }\end{array}$ \\
\hline 1 & Positivo & $\begin{array}{l}\text { Neutro/ } \\
\text { Positivo }\end{array}$ & Neutro & Positivo & Inexistente & Neutro \\
\hline 2 & Negativo & Positivo & Neutro & $\begin{array}{l}\text { Inexistente/ } \\
\text { Positivo }\end{array}$ & $\begin{array}{l}\text { Inexistente } \\
\text { Positivo }\end{array}$ & $\begin{array}{l}\text { Neutro/ } \\
\text { Positivo }\end{array}$ \\
\hline 3 & $\begin{array}{l}\text { Neutro/ } \\
\text { Negativo }\end{array}$ & $\begin{array}{l}\text { Neutro/ } \\
\text { Negativo }\end{array}$ & Positivo & Inexistente & Inexistente & Neutro \\
\hline 4 & Negativo & Negativo & Inexistente & Inexistente & $\begin{array}{l}\text { Positivo/ } \\
\text { Neutro }\end{array}$ & Neutro \\
\hline 5 & Negativo & Negativo & Negativo & $\begin{array}{l}\text { Inexistente/ } \\
\text { Neutro }\end{array}$ & $\begin{array}{l}\text { Positivo/ } \\
\text { Neutro }\end{array}$ & Neutro \\
\hline 6 & $\begin{array}{l}\text { Positivo/ } \\
\text { Neutro }\end{array}$ & Negativo & Inexistente & Inexistente & Inexistente & Negativo \\
\hline
\end{tabular}

Fonte: Bittar (2011).

Os jovens das três últimas configuraçôes, por sua vez, apresentam trajetória escolar descontínua, mudança de percurso em sentido negativo ou ausência de projetos escolares e profissionais. A configuração 4 se distingue das duas últimas pela questão de gênero. As dificuldades vivenciadas por essas jovens estão associadas a eventos que costumam afetar mais fortemente as mulheres. Os papéis desempenhados no interior da família geram constrangimentos ao seu desenvolvimento escolar e profissional. Por outro lado, elas não encontram elos em outras esferas que a ajudem a superar os limites impostos pela família. Como resultado, notamos um retraimento em relação à escola e aos assuntos relacionados com esse espaço. Elas enfrentam dificuldades na construção da sua experiência escolar: sucumbem aos julgamentos escolares, ocupam a periferia da sala de aula.

Vale ressaltar, contudo, que para uma das entrevistadas a participação em um programa social apontou a possibilidade de mudança em sua traje- tória escolar. A experiência vivenciada no programa social e os vínculos ali estabelecidos permitiram à jovem sair da situação de "invisibilidade". Houve uma ampliação dos laços e maior participação em espaços sociais. No entanto, a (curta) duração do programa social em questão pode ser insuficiente para a superação das dificuldades enfrentadas.

$\mathrm{Na}$ configuração 5, diversos elementos parecem se associar e afetar de forma negativa a trajetória escolar desses jovens. Sua história familiar é marcada por crises, mudanças e separaçôes. As relações e as experiências escolares reforçam o efeito negativo da família, gerando significativas e, em dois casos, definitivas rupturas em seus percursos educacionais. A inserção precária no mercado de trabalho, por sua vez, além de prejudicar seu desempenho, não resulta em novos laços de apoio. Os únicos elos empenhados em reverter o processo de exclusão escolar desses jovens são os constituídos nos programas sociais. Em dois casos, eles parecem impedir a ruptura definitiva com a escola. 
Já na configuração 6 dois elementos contribuem para a descontinuidade nas trajetórias escolares dos jovens: o ingresso no mundo do crime e a relação tensa com a equipe escolar. Os elos estabelecidos nas esferas da vizinhança, do lazer e da escola com integrantes do "mundo do crime" provocam rupturas em suas trajetórias educacionais. Os laços escolares, por sua vez, reforçam o elo do jovem com o crime ao excluí-lo do cotidiano escolar. Os vínculos familiares não são capazes de romper com os elos que propiciaram sua inserção no "mundo do crime", mas parecem impedir a ruptura definitiva com a escola. No caso de um dos jovens, as duas crises vivenciadas foram fatores que estimularam seu ingresso no crime e a deterioração das relações escolares.

Os jovens dessas duas últimas configurações podem ser incluídos no quarto tipo de experiência escolar descrito por Dubet (1998). Esses alunos reagem aos julgamentos escolares com violência ou afastamento da rotina escolar. A forma que encontram de resguardar a autoestima ou a dignidade é se voltarem contra a escola. O resultado final, na maioria dos casos, tem sido o abandono do jogo ou a ruptura definitiva com a escola.

\section{Conclusão}

Nestas considerações finais, sumarizamos os principais achados deste artigo. O objetivo era explorar os mecanismos e as dinâmicas que podem afetar as trajetórias escolares dos jovens, provocando mudanças ou fortalecendo sua direção inicial. Buscamos compreender a heterogeneidade encontrada em uma mesma escola, localizada em um distrito da periferia de São Paulo.

Apesar de nos limitarmos a uma única escola, encontramos entre os entrevistados heterogeneidade em termos de atributos individuais e de dimensões socioeconômicas e culturais. Os jovens apresentam diferenças quanto à idade, à cor, ao gênero, à renda familiar, às condições de moradia, ao tipo de família, à escolaridade e à situação dos pais ou responsáveis no mercado de trabalho. Esses fatores certamente influenciam a trajetória escolar desses jovens. Por outro lado, identificamos jovens que apresentam atributos e condições socioeconômicas similares, mas trajetó- rias escolares distintas. Nestes casos, as relações estabelecidas com os elos das esferas de sociabilidade e as formas como lidaram com as situações de crise parecem explicar as diferenças encontradas.

A trajetória escolar contínua ou a mudança de percurso em sentido positivo ocorre quando pelo menos uma das seguintes esferas de sociabilidade apresenta efeito positivo: a família, a escola ou o trabalho. As duas primeiras esferas parecem confirmar a importância dos laços estabelecidos nas instituições tradicionais para a "adequação" do comportamento do jovem às expectativas da equipe escolar, a ausência de conflito entre seus interesses e os da escola e o bom desempenho escolar. Já a esfera do trabalho aponta uma novidade. Embora não esteja entre as instituições tradicionais de formação do indivíduo, os vínculos estabelecidos nesta esfera podem estimular a mobilização escolar e a mudança positiva na trajetória escolar. Os elos estabelecidos na esfera religiosa, outra instituição clássica, atuaram de forma conjunta com a família na primeira configuração e com a escola na segunda, como condição para a definição do percurso desses jovens.

O efeito negativo dos elos estabelecidos na esfera escolar, por sua vez, está associado, em todos os casos, à trajetória descontínua ou à mudança de percurso em sentido negativo. Contudo, esses vínculos não atuam sozinhos em nenhuma das configuraçôes. Os elos familiares, profissionais e estabelecidos no "mundo do crime" atuam de forma combinada com os escolares, resultando em uma trajetória descontínua. A incapacidade da equipe escolar de lidar com a realidade - em que as linguagens e saberes apropriados em espaços alternativos à escola "invadem" o seu mundo - e os conflitos daí decorrentes são importantes elementos explicativos da descontinuidade da trajetória escolar.

Já os efeitos dos programas sociais sobre a trajetória escolar dos jovens não é homogêneo. Ele aparece no relato de um jovem da segunda configuração, de uma da quarta e de todos os rapazes da quinta configuração. Neste último grupo, identificamos um importante esforço dos elos estabelecidos nos programas sociais para reverter a trajetória negativa. Em dois casos, eles parecem impedir a ruptura definitiva com a escola. Nos outros dois, o empenho não é suficiente para reverter a exclusão escolar. A instabilidade e a curta duração desses programas, além 
da inexistência de canais de diálogo entre a equipe escolar e os técnicos das entidades sociais do bairro, podem ser alguns dos limitadores da ação dessa esfera. Por fim, vale ressaltar que o efeito da crise sobre a trajetória escolar do jovem depende da forma como ela é vivenciada e do apoio recebido dos vínculos.

\section{Notas}

1 O balanço realizado por Dayrell et al. (2009) da produção discente na pós-graduação brasileira sobre o tema Juventude e Escola no Período entre 1999 e 2006 levantou 188 trabalhos.

2 Selecionamos alguns trabalhos sobre o tema.

3 Participação nas atividades escolares, preocupação com os estudos.

4 Restringimo-nos ao ensino médio por ser um momento da escolarização fortemente relacionado com a juventude.

5 Em 2009, a escola recebeu 831 matrículas no ensino médio regular e 472 matrículas na Educação de Jovens e Adultos

6 Em 2009, ela recebeu 283 matrículas no segundo ciclo do ensino fundamental.

7 Não foi possível classificar um dos jovens entrevistados em nenhuma das configurações.

8 A análise dos dados coletados implicou um longo esforço para esquadrinhar o conteúdo dos depoimentos. Foi realizado um trabalho de seleção e tratamento das entrevistas e organização dos dados de forma a transformar as narrativas em categorias de análise.

9 De acordo com Briggs (2001), os elos sociais podem desempenhar três funçôes: funcionar como pontes que permitem a mobilidade social; ou como fonte de apoio social, garantindo a sobrevivência; ou ainda ter efeitos negativos sobre resultados individuais e familiares em termos de educação e empregos.

10 É bastante comum que os alunos com dificuldade de aprendizagem sejam retidos por vários anos na $1^{\text {a }}$ série do ensino médio, concentrando-se em poucas turmas.

11 Os técnicos dos programas sociais ajudam esses jovens a superar as crises familiares, obter documentos, entre outras demandas.

12 Denominamos "mundo do crime" porque esses jovens fazem parte de uma rede de sociabilidade movida pela possibilidade de obtenção de renda e ampliação do status individual no grupo através de atividades cri- minais, como narcotráfico, roubo de carros e assaltos.

13 A participação num pequeno assalto ou o trabalho de dois dias da semana num dos pontos de venda de drogas rendem uma quantia superior ao salário de um mês de trabalho árduo.

14 De acordo com Bourdieu (1983), um dos fatores que leva à inserção precoce dos adolescentes das classes populares no mercado de trabalho é o desejo de atingir o estatuto de adulto: ter dinheiro é muito importante para se afirmar em relação aos colegas e às meninas e para ser reconhecido como homem.

15 A Fundação Centro de Atendimento Socioeducativo ao Adolescente (Casa) presta assistência a jovens de 12 a 21 anos incompletos inseridos nas medidas socioeducativas de privação de liberdade (internação) e semiliberdade (http://www.fundacaocasa.sp.gov.br).

\section{BIBLIOGRAFIA}

ALGEBAILE, Eveline Bertino. (2004), Escola pública e pobreza: expansão escolar e formação $d a$ escola dos pobres no Brasil. Rio de Janeiro, tese de doutorado, Faculdade de Educação da Universidade Federal Fluminense.

AQUINO, Julio Roberto Groppa. (2007), "As transgressōes da ordem escolar”. Educação, 1: 56-67.

BARROS, Ricardo Paes et al. (2001), "Determinantes do desempenho educacional no Brasil". Texto para discussão, n. 834, Ipea.

BERTAUX, Daniel. (2005), Los relatos de vida: perspectiva etnosociológica. Barcelona, Bellaterra.

BITTAR, Mariana. (2011), Trajetórias educacionais dos jovens residentes num distrito com elevada vulnerabilidade juvenil. Tese de doutorado. Faculdade de Filosofia, Letras e Ciências Humanas da Universidade de São Paulo.

BOURDIEU, Pierre. (1983), "A juventude é apenas uma palavra", in P. Bourdieu (org.), Questôes de sociologia, Rio de Janeiro, Marco Zero.

BRIGGS, Xavier de Souza. (2001), "Ties that bind, bridge and constrain: social capital and segregation in the American metropolis". Trabalho apresentado no seminário Segregation and the City, Lincoln Institute for Land Policy.

CÉSAR, Cibele Comini \& SOARES, José Francisco. (2001), "Desigualdades acadêmicas induzi- 
das pelo contexto escolar". Revista Brasileira de Estudos de População, 18 (12): 97-110.

CHARLOT, Bernard. (1996), "Relação com o saber e com a escola entre estudantes de periferia”. Cadernos de Pesquisa, 97: 47-63.

. (2000), Da relação com o saber: elementos para uma teoria. Porto Alegre, Artmed.

DAYRELL, Juarez. (1996), "A escola como espaço sciocultural”, in J. Dayrell (org.), Múltiplos olhares sobre educação e cultura, Belo Horizonte, Editora UFMG.

et al. (2009), "Juventude e escola", in M. P. Sposito (org.), O estado da arte sobre juventude na pós-graduação brasileira: educação, ciências sociais e serviço social (1999-2006), Belo Horizonte, Argumentum.

DOMINGUEZ, Silvia. (2004), "Estrategias de movilidad social: el desarrollo de redes para el progreso personal". Revista Hispana para el Análisis de Redes Sociales, 7 (1): 1-46.

DUBET, François. (1998), "A formação dos indivíduos: a desinstitucionalização". Contemporaneidade e Educação, 3 (3): 27-33.

(2003), "A escola e a exclusão". Cadernos de Pesquisa, 119: 29-45.

(2005), "Pour une conception dialogique de l'individu". Espaces Temps. Disponível em http://www.espacestemps.net/articles/conception-dialogique-individu/, consultado em 2014. (2008), O que é uma escola justa? A escola das oportunidades. São Paulo, Cortez.

DURLAUF, Steven N. (2001), "The memberships theory of poverty: the role of group affiliations in determining socioeconomic outcomes", in S. H. Danziger e R. H. Haveman (eds.), Understanding poverty, Nova York, Russel Sage Foundation.

ELIAS, Norbert. (2008), Introdução à sociologia. Lisboa, Edições 70.

FELTRAN, Gabriel de Santis. (2008), Fronteiras de tensão: um estudo sobre politica e violência nas periferias de São Paulo. Campinas, tese de doutorado, Instituto de Filosofia e Ciências Humanas da Universidade Estadual de Campinas.

GUIMARÃES, Nadya Araújo. (2005), “Trabalho: uma categoria chave no imaginário juvenil?”, in H. W. Abramo e P. P. M. Branco (orgs.), Retratos da juventude brasileira: análises de uma pesquisa nacional, São Paulo, Fundação Perseu Abramo.

LACERDA, Wânia Maria Guimarães. (2006), Famílias e filhos na construção de trajetórias escolares pouco prováveis: o caso dos iteanos. Rio de Janeiro, tese de doutorado, Faculdade de Educação da Universidade Federal Fluminense.

LAHIRE, Bernard. (2008), Sucesso escolar nos meios populares: as razões do improvável. São Paulo, Ática.

MANTOVANINI, Maria Cristina. (2001), Professores e alunos problema: um círculo vicioso. São Paulo, Casa do Psicólogo.

MENEZES, Naercio Filho \& RIBEIRO, Fernanda Patriota. (2009), "Os determinantes da melhoria do rendimento escolar", in F. VELOSO et al. (org.), Educação básica no Brasil: construindo $o$ pais do futuro, Rio de Janeiro, Elsevier.

PAIS, José Machado. (1990), "Lazeres e sociabilidades juvenis: um ensaio de análise etnográfica”. Análise Social, XXV (108-109): 591-644.

PEREIRA, Adriana da Silva Alves. (2005), Sucesso escolar nos meios populares: mobilização pessoal e estratégias familiares. Belo Horizonte, tese de mestrado, Faculdade de Educação da Pontifícia Universidade Católica de Minas Gerais.

PEREIRA, Alexandre Barbosa. (2010), "A maior zoeira: experiências juvenis na periferia de São Paulo. São Paulo, tese de doutorado, Faculdade de Filosofia, Letras e Ciências Humanas da Universidade de São Paulo.

SÁ EARP, Maria de Lourdes. (2006), A cultura da repetência em escolas cariocas. Rio de Janeiro, tese de doutorado, Instituto de Filosofia e Ciências Sociais da Universidade Federal do Rio de Janeiro.

SEADE. (2002), "Índice de vulnerabilidade juvenil”. São Paulo, Fundação Seade. Disponível em http://produtos.seade.gov.br/produtos/ivj/, consultado em 2014.

. (2007), "Evolução do índice de vulnerabilidade juvenil: 2000-2005”. São Paulo, Fundação Seade. Disponível em http://produtos. seade.gov.br/produtos/ivj/ivj_2000_05.pdf, consultado em 2014.

SETTON, Maria da Graça Jacintho. (2002), "Família, escola e mídia: um campo com novas 
configurações”. Educação e Pesquisa, 28 (1): 107-116.

. (2008), "As religióes como agentes de socialização". Cadernos Ceru, 19 (2): 15-25, série 2.

SILVA, Jailson de Souza. (2003), Por que uns e não outros? Caminhada de estudantes da Maré para a Universidade. Rio de Janeiro, 7 Letras.

SILVA, Rosemeire Reis. (2006), Encontros e desencontros: a relação dos jovens/novos alunos do ensino médio em moratória com os saberes escolares. São Paulo, tese de doutorado, Faculdade de Educação da Universidade de São Paulo.

SPOSITO, Marília Pontes. (2003), "Uma perspectiva não escolar no estudo sociológico da escola”. Revista USP, 57: 210-226.

. (2004), "(Des)encontros entre os jovens e a escola”, in G. Frigotto e M. Ciavatta (orgs.), Ensino Médio: ciência, cultura e trabalho, Brasília, MEC, Semtec, vol. 1.

. (2009), O estado da arte sobre juventude na pós-graduação brasileira: educação, ciências sociais e serviço social (1999-2006). Belo Horizonte, Argumentum.

TORRES, Haroldo da Gama \& GOMES, Sandra. (2002), "Desigualdade educacional e segregação social na Região Metropolitana de São Paulo". Novos Estudos Cebrap, 64: 132-140. ; FERREIRA, Maria Paula \& GOMES, Sandra. (2005), "Educação e segregação social: explorando o efeito das relações de vizinhança”, in E. Marques e H. Torres da Gama (orgs.), São Paulo, segregação pobreza e desigualdades sociais, São Paulo, Editora Senac. 


\section{TRAJETÓRIAS EDUCACIONAIS DE JOVENS RESIDENTES EM UM DISTRITO DA PERIFERIA DE SÁO PAULO}

\section{Mariana Bittar}

Palavras-chave: Jovens; Trajetória educacional; Vulnerabilidade juvenil; Esferas de sociabilidade.

Este artigo tem por objetivos explorar de que forma os elos estabelecidos nas esferas de sociabilidade em que os jovens estão inseridos se articulam e afetam as suas trajetórias educacionais, provocando mudanças ou fortalecendo sua direção inicial, e em que medida situações de crise podem afetar sua relação com esses elos e, consequentemente, seus percursos. Diferenças em termos de atributos individuais e de dimensões socioeconômicas e culturais influenciam as trajetórias escolares. No entanto, identificamos jovens com atributos e condiçôes socioeconômicas similares, mas trajetórias distintas. Nesses casos, as relações estabelecidas com os elos das esferas de sociabilidade e as formas como lidaram com as situaçōes de crise parecem explicar as diferenças encontradas.

\section{EDUCATIONAL TRAJECTORIES OF YOUNG RESIDENTS IN A DISTRICT OF SAO PAULO'S PERIPHERY}

\section{Mariana Bittar}

Keywords: Youth; Educational trajectory; Youth vulnerability; Spheres of sociability.

The paper aims at exploring how the connections established in the youngsters' spheres of sociability affect their educational trajectories, either provoking changes or strengthening their initial orientation. It deals as well as with the discussion related to the extent in which situations of crisis can affect their relation with those connections and, consequently, the course of their educational development. Although limited to a single school, the study found heterogeneity among respondents in terms of their individual attributes and the socioeconomic and cultural dimensions characterizing them, factors that influence the educational trajectories. However, young people were identified with similar socioeconomic and cultural conditions, but with distinct trajectories. In these cases, the differences found can be explained by the relationship established with connections in spheres of sociability and the ways in which crisis situations were dealt with.
TRAJECTOIRES ÉDUCATIVES DE JEUNES DE LA BANLIEUE DE SÃO PAULO

\section{Mariana Bittar}

Mots-clés: Jeunes; Trajectoire éducative; Vulnérabilité juvénile; Sphères de sociabilité.

Cet article propose de voir si les liens établis par les jeunes dans les sphères de sociabilité où ils sont insérés ont des conséquences sur leurs trajectoires éducatives, autrement dit s'ils les modifient ou les consolident. Il vise à comprendre dans quelle mesure des situations de crise peuvent affecter leur rapport à ces liens et, par voie de conséquence, leurs parcours scolaires. Il apparaît que des différences en termes de caractéristiques individuelles et de dimensions socio-économico-culturelles influencent les trajectoires scolaires. Néanmoins, il existe aussi des jeunes aux caractéristiques et aux dimensions similaires mais aux trajectoires différentes. Dans ces cas-là, les relations établies avec les liens des sphères de sociabilité et la manière de faire face aux situations de crise semblent expliquer les différences observées. 